\title{
Stretch-Activated Ion Channels in Growth Cones of Snail Neurons
}

\author{
Wade J. Sigurdson and Catherine E. Morris \\ Department of Biology, University of Ottawa, Ottawa, Ontario, Canada K1N 6N5
}

\begin{abstract}
Using single-channel recording, we show that neurons contain ion channels sensitive to membrane tension. Neurons isolated from the snail, Lymnaea stagnalis, actively rearborized in culture yielding cell bodies and growth cones suitable for patch clamping. All neurons contained, in both their soma and growth cones (at a density of $\sim 1-2 \mu \mathrm{m}^{-2}$ ), stretch-activated channels highly selective for $\mathrm{K}^{+}$. The presence of this mechanosensitive channel in the motile region of the neuron, a region characterized by insertion of new membrane-the growth cone-is of particular interest. Under physiological conditions, the channel was permeable to $\mathrm{K}^{+}$, but not to $\mathrm{Na}^{+}$or $\mathrm{Cl}^{-}$. Its conductance to $\mathrm{K}^{+}$under these conditions was $\sim 44 \mathrm{pS}$. Channel activation was steeply dependent on membrane tension, showing thresholds at between -50 to $-100 \mathrm{~mm} \mathrm{Hg}$ (suction was applied through the recording pipette). Kinetic analysis indicated that the stretch-dependent increase in the channel's open probability was related to a long closed state rather than to one of the open states. Given the importance of $\mathrm{Ca}^{2+}$ in the regulation of growth cone motility, we speculate that this stretchactivated $\mathrm{K}^{+}$channel could play a role in neurite elongation by a tension-dependent modulation of membrane voltage which in turn would act on voltage-gated $\mathrm{Ca}^{2+}$ channels.
\end{abstract}

The idea that cells which are not specialized mechanosensors should possess stretch-sensitive ion channels still seems novel, but following the first observation of such channels in skeletal muscle (Guharay and Sachs, 1984), similar channels have been described in cells as diverse as bacteria, yeast, plant protoplasts, lens epithelium, smooth muscle, endothelial cells (reviewed by Kullberg, 1987; Sachs, 1988), and teleost embryos (Medina and Bregestovski, 1988).

Here we report that molluscan neurons contain stretch-activated channels. These channels occurred in the cell body, but more interestingly yet, in the mechanically active part of the cell, the growth cone. They were ubiquitous rather than confined to identified neurons. Isolated in culture, Lymnaea neurons actively put out new processes with growth cones that, like those in other gastropod neurons (Siegelbaum et al., 1986), are large enough for single-channel recording.

Neurite elongation and cell locomotion are related processes, probably using the common underlying mechanisms of exocytosis and actin-myosin contractions (Lackie, 1986; Bray, 1987;

Received Oct. 31, 1988; revised Jan. 16, 1989; accepted Jan. 19,1989.

This work was supported by the Natural Sciences and Engineering Research Council of Canada, and the Muscular Dystrophy Association of Canada.

Correspondence should be addressed to Catherine E. Morris, Department of Biology, University of Ottawa, 30 Somerset East, Ottawa, Ontario, Canada K1N 6N5.

Copyright $\subset 1989$ Society for Neuroscience $0270-6474 / 89 / 082801-08 \$ 02.00 / 0$
Kater et al., 1988). Models of these processes therefore require that $\mathrm{Ca}^{2+}$ concentrations be controlled within narrow limits (Kater et al., 1988). Snail neurons have been instrumental in showing how neurotransmitters and electrical activity, through indirect effects on intracellular $\mathrm{Ca}^{2+}$, control growth cone motility. Given the strong precedent for regulation of neuronal $\mathrm{Ca}^{2+}$ levels by $\mathrm{K}^{+}$channels (Siegelbaum et al., 1986), stretch-activated channels that are $\mathrm{K}^{+}$selective would naturally be of special interest in growth cones. Growth cone motility, by definition, is a mechanical process, so that neurite membranes should experience tension changes during growth. Stretch-sensitive channels in growth cones could provide a link between this membrane tension and-via membrane voltage-transmembrane $\mathrm{Ca}^{2+}$ fluxes.

Preliminary communications describing stretch-activated channels in snail neurons (Sigurdson et al., 1987b; Bedard et al., 1988) and in neuroblastoma (Falke and Misler, 1988) have appeared.

\section{Materials and Methods}

Lymnaea stagnalis were collected locally or purchased from Blades Biological (Edenbridge, England). Sterile isotonic normal saline (NS) ( $50 \mathrm{~mm} \mathrm{NaCl}, 1.6 \mathrm{~mm} \mathrm{KCl}, 3.5 \mathrm{~mm} \mathrm{CaCl}, 2.0 \mathrm{~mm} \mathrm{MgCl}$, $5 \mathrm{~mm} \mathrm{HEPES}$ 5 mM glucose, pH 7.6, adjusted with $\mathrm{NaOH}$ ) supplemented with penicillin $(500 \mathrm{IU} / \mathrm{ml})$ and streptomycin $(500 \mu \mathrm{g} / \mathrm{ml})$ was used as the culture medium. Pipette solutions were either antibiotic-frec NS or $50 \mathrm{~mm} \mathrm{KCl}$ saline (50 mM KCl, $1 \mathrm{~mm} \mathrm{CaCl}_{2}, 5 \mathrm{~mm}$ HEPES, pH 7.6). A low $\mathrm{Ca}^{2+}$ saline (buffered to $10^{-8} \mathrm{M} \mathrm{Ca}^{2+} ; 60 \mathrm{mM} \mathrm{KCl}, 2 \mathrm{mM} \mathrm{MgCl}_{2}, 0.2 \mathrm{mM} \mathrm{CaCl}_{2}$, $2.2 \mathrm{~mm}$ EGTA, 5 mM HEPES, pH 7.6) was used to perfuse inside-out patches in some experiments. Neurons from the circumoesophageal ganglia were isolated by first loosening the connective tissue sheath in $0.25 \%$ protease (Sigma) (40 min agitation) followed by mechanical dispersion. Neurons from individual ganglionic masses were then dispersed directly on to coverslips (recording chamber bottoms). Chambers were detergent-washed, rinsed thoroughly with distilled water, surface-sterilized with $70 \%$ ethanol, and then dried in a $60^{\circ} \mathrm{C}$ oven for at least $2 \mathrm{hr}$ before use. Cell adhesion and spreading on the glass substratum was generally good provided the amount of cellular debris was minimized during dispersal.

Standard single-channel recording techniques were employed (Hamill et al., 1981) to record from the neuron cell membrane. Patch electrodes were pulled (Kopf 750 pipette puller) from Corning 7052 capillary tubes (Garner Glass Co., Claremont, CA; i.d. $=0.8 \mathrm{~mm}$, o.d. $=1.65 \mathrm{~mm}$ ), fire-polished, and filled with NS, with NS plus $1 \mathrm{~mm}$ quinidine (Sigma), or $50 \mathrm{~mm} \mathrm{KCl} \mathrm{saline.} \mathrm{Pipette} \mathrm{tip} \mathrm{openings} \mathrm{were} \mathrm{estimated} \mathrm{to} \mathrm{be} \mathrm{a} \mathrm{max-}$ imum of $2 \mu \mathrm{m}$ in diameter prior to fire-polishing and had a mean bubble number of $4 \pm 0.6, n=5$ (Corey and Stevens, 1983). Suction applied to the patch pipette through the sidearm of the electrode holder was monitored by a Bio-Tek pressure transducer (Bio-Tek Instruments, Burlington, VT).

Single-channel currents were recorded using a patch-clamp amplifier (Axon Instruments, Burlingame, CA), filtered at $10 \mathrm{kHz}$, and stored on video tape using a PCM-1 (Medical Systems, Greenvale, NY) digitizing unit. For analysis of current amplitudes, data were filtered at 1 or 2 $\mathrm{kHz}$, displayed on a digital storage oscilloscope and the amplitudes of at least 10 individual events directly measured from the display. For analysis of open probabilities $[P(\mathrm{O})]$ and for mean open and closed times, data were filtered at $2 \mathrm{kHz}$ and digitized at $0.1 \mathrm{msec} /$ point $(5$ 

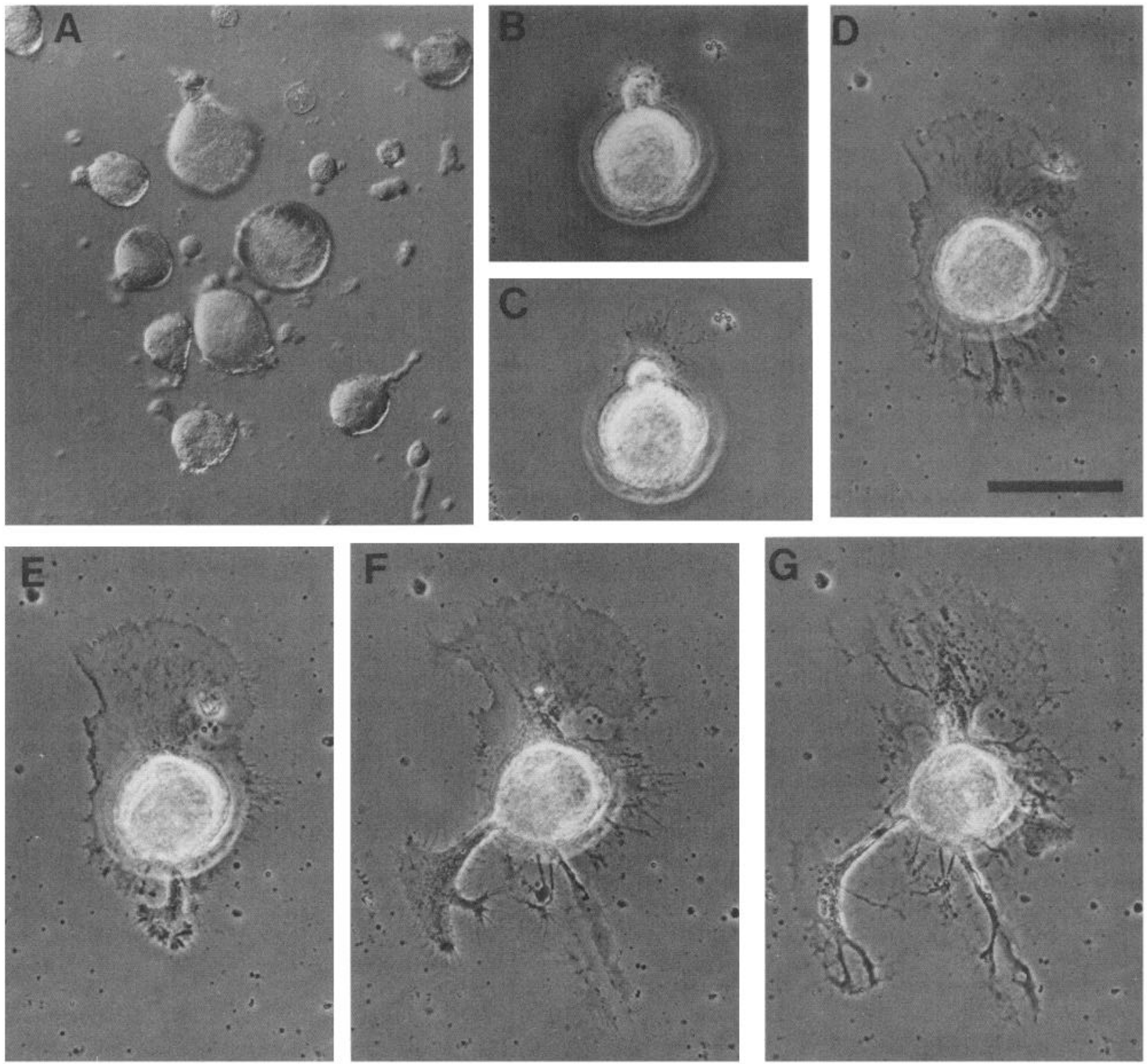

Figure 1. Timecourse of neurite growth. A, Freshly isolated unidentified Lymnaea neurons. DIC optics; scale bar, $106 \mu \mathrm{m}$. $B-G$, Neurite development of one cell from isolation until day $3 . B, 20 \mathrm{~min} . C, 1 \mathrm{hr} . D, 21.5 \mathrm{hr} . E, 24 \mathrm{hr} . F, 45.5 \mathrm{hr}$. $G, 68 \mathrm{hr}$. Phase contrast optics; scale bar, 54 $\mu \mathrm{m}$.

times the filter cutoff frequency). An event-detection program run on a DEC 11/23 computer produced an idealized record of the open and closed times, thus allowing determination of the proportion of time the channels spent open. When intense channel activity precluded accurate event detection, an index of $P(\mathrm{O})$ was determined by integrating the current record over a known time interval and dividing by the singlechannel current. The true number $(n)$ of channels in the patch is unknown, hence, in both approaches, $P(O)$ is reported as (Sigurdson et al., 1987a):

$$
\text { Index } P(\mathrm{O})=N_{1} P_{1}+N_{2} P_{2}+\ldots+N_{n} P_{n} \text {, }
$$

where $N_{i}$ is the number of channels simultaneously open and $P_{i}$ the proportion of time spent with $N_{i}$ channels open. Dividing index $P(\mathrm{O})$ by $n$, were it known, would give $P(\mathrm{O})$, the open probability for a single channel.

Curve-fitting procedures used to determine time constants associated with the open and closed times have been described previously (Sigurdson et al., 1987a).
For current/voltage $(I / V)$ relations of cell-attached patches, the membrane voltage $\left(V_{m}\right)$ was taken to be

$$
V_{m}=V_{\text {rest }}-V_{p},
$$

where $V_{p}$ is the pipette holding potential and $V_{\text {rest }}$ the assumed resting potential of the cell. $V_{\text {resi }}$, obtained from intracellular measurements, was $-50 \pm 1.9 \mathrm{mV}$ (SEM, $n=32$ ).

Photomicrographs were made using an Olympus IMT-2 inverted microscope employing phase-contrast or Nomarski differential interference contrast (DIC) optics. Cells were cultured, and all recordings made at room temperature $\left(18-23^{\circ} \mathrm{C}\right)$.

\section{Results}

Rearborization of the isolated neurons

Isolation disrupted the in vivo structure of neurons. Freshly dissociated, neurons consisted only of a cell body, sometimes 

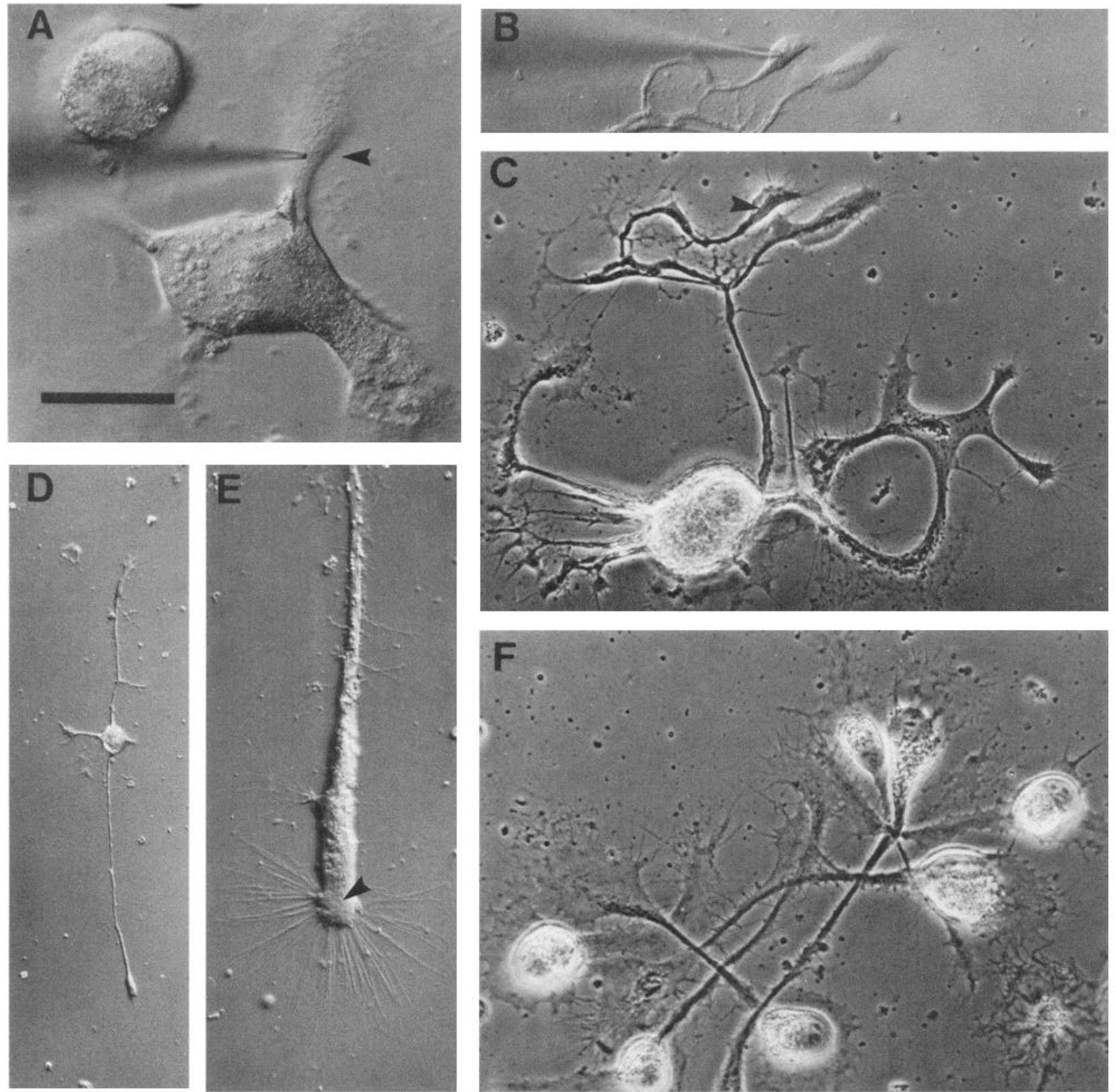

Figure 2. Lymnaea neurons several days in culture. A, Neurons $5 \mathrm{~d}$ after isolation. Note patch pipette (arrowhead) located on a process close to the cell body. SAK channels were observed during recordings made at this point. $B$, Patch pipette on growth cone from the cell in $C$. Recordings from this patch exhibited SAK channels. $C$, Day 3 cell with numerous neurites terminated by growth cones with lamellae and microspikes. Arrowhead marks the location of the patch pipette pictured in $B$. $D$, A very long $(>720 \mu \mathrm{m})$ day 3 neuron. Patch recordings from the growth cone (lower part of plate) and the cell body both showed SAK channels (see Fig. 3). E, Higher magnification view of the patched growth cone (with numerous microspikes) in $D$. Patch location indicated by arrowhead. $F$, Day 5 neurons showing extensive neurite development with overlapping of processes. As in other cells, growth cones are well-developed, many containing large veil areas with protruding microspikes. DIC optics for $A, C, D, E ;$ Phase contrast optics for $B, F$. Scale bar for $A, B, C, F, 54 \mu \mathrm{m}$; for $D, 208 \mu \mathrm{m}$; for $E, 36 \mu \mathrm{m}$.

bearing a short axon stump (Fig. $1 A, B$ ). For our purposes, this was advantageous, because the subsequent rearborization provided an opportunity to record from membrane that, we could assume, was newly elaborated. To illustrate some of the dynamics of regrowth of isolated Lymnaea neurons under the minimal culture conditions used (cf. Kater and Mattson, 1988), Figure $1, B-G$, follows a cell for $68 \mathrm{hr}$ postdissociation. The axon remnant (Fig. $1 B$ ) became the first attachment site 20 min after isolation. In the next hour, a lamella appeared (Fig. 1C), then spread extensively. The cell became firmly attached (Fig. 1D, $21.5 \mathrm{hr}$ ), as indicated by its stability during jarring movements of the culture dish. Over the same period, small neurites with microspikes began to extend from the opposite side of the soma (Fig. 1D). One of these neurites rapidly broadened into a growth cone (Fig. $1 E, 24 \mathrm{hr}$ ), which extended for $\sim 70 \mu \mathrm{m}$ before retracting (not shown). By $46 \mathrm{hr}$, another neurite had formed and produced a much larger growth cone (Fig. $1 F$ ), which continued to elongate and branch (Fig. $1 G, 68 \mathrm{hr}$ ). Meanwhile the neurite 

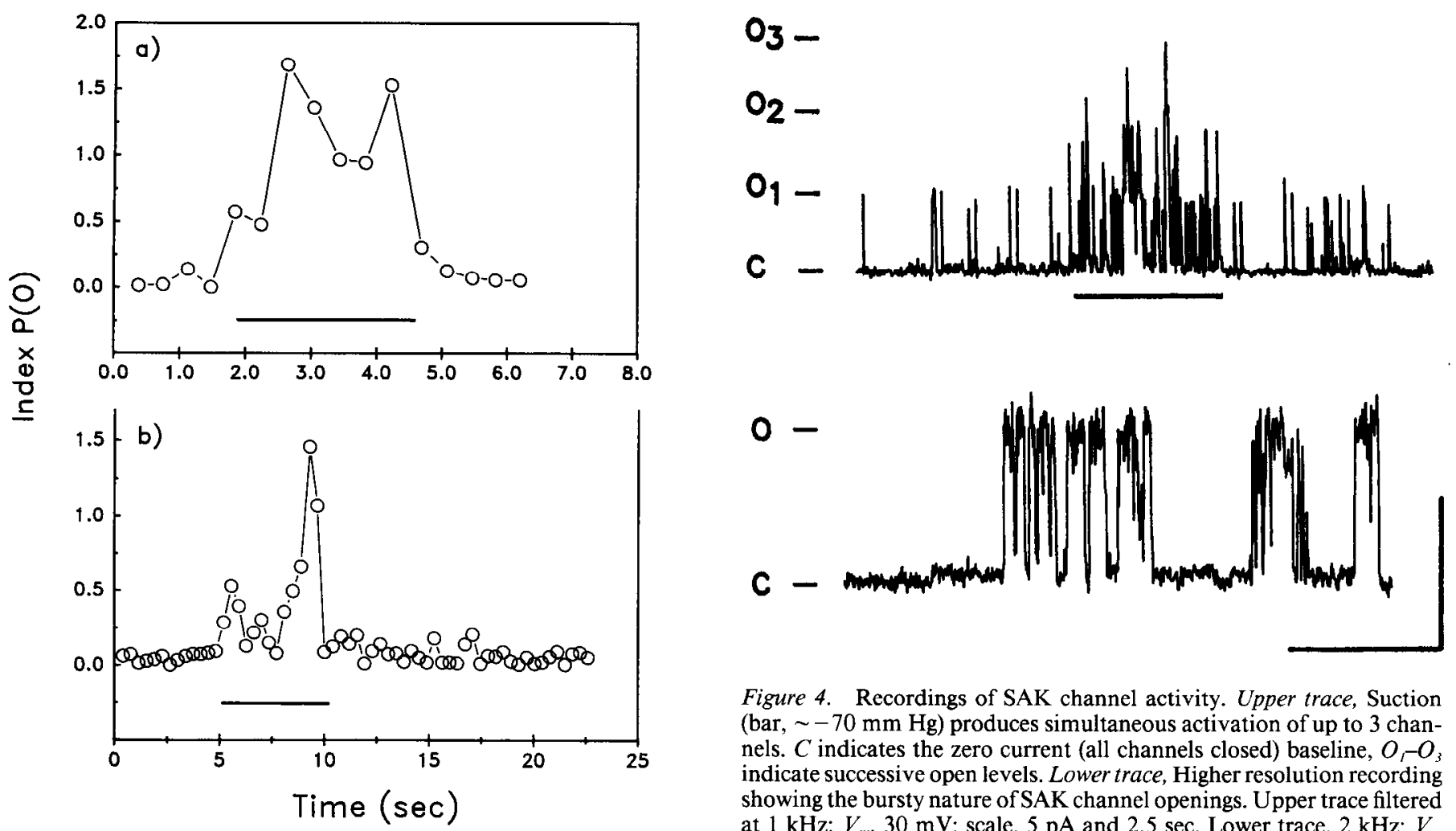

Figure 4. Recordings of SAK channel activity. Upper trace, Suction (bar, $\sim-70 \mathrm{~mm} \mathrm{Hg}$ ) produces simultaneous activation of up to 3 channels. $\mathrm{C}$ indicates the zero current (all channels closed) baseline, $\mathrm{O}_{1}-\mathrm{O}_{3}$ indicate successive open levels. Lower trace, Higher resolution recording showing the bursty nature of SAK channel openings. Upper trace filtered at $1 \mathrm{kHz} ; V_{m}, 30 \mathrm{mV}$; scale, $5 \mathrm{pA}$ and $2.5 \mathrm{sec}$. Lower trace, $2 \mathrm{kHz} ; V_{m}$ $=70 \mathrm{mV}$; scale, $5 \mathrm{pA}$ and $50 \mathrm{msec}$.

Figure 3. Stretch increases the open probability of SAK channels from the cell body and growth cone. $a$. Cell body and $b$, growth cone of the neuron pictured in Figure $2 \mathrm{D}$. Bars indicate suction of $\sim 50$ to 70 $\mathrm{mm} \mathrm{Hg}$, which was submaximal for this patch. $V_{m}, 70 \mathrm{mV}$ for both patches.

(Fig. 1E) that had retracted, reextended. Throughout the neuron's regrowth process, the large lamella established from the axon remnant was relatively stable, with major neurite and growth cone formation occurring on the opposite side of the soma.

Most, but not all isolated cells attached and began spreading within minutes. Figure $2 A$ shows 2 cells $5 \mathrm{~d}$ in culture, one which merely persisted, another which rearborized. The gamut of rearborization patterns was wide. At one extreme (Fig. 2, $B$, $C)$, cell bodies had multiple neurites with subbranches. Some cells were dominated by 2 long neurites (Fig. 2, D,E), whereas others were essentially monopolar (Fig. $2 F$ ). As the figures show, neurites were terminated by growth cones from which extended microspikes (Fig. 2, $B, E$ ) and/or lamellae (Fig. 2, $B, F$ ). Recordings were made from cell bodies and growth cones in neurons of all morphological types.

\section{Stretch-activated $K^{+}$(SAK) channel distribution}

Stretch-activation of the (SAK) channel was observed in cellattached and excised (inside-out) patches. Except were specifically noted data were obtained from cell-attached patches using pipettes containing antibiotic-free NS.

SAK channels were ubiquitous. They were observed in each of 6 freshly isolated neurons tested at $0.3-2.0 \mathrm{hr}$ postdissociation, as well as in the cell bodies of all older neurons tested. They were observed in broad dilations near the cell body (Fig. $2 A$ ) in older, spread-out cells. They were observed in regions of extensive neurite and growth cone formation (Fig. 2, B, C). Figure $2 D$ shows an actively advancing growth cone approxi-

mately $370 \mu \mathrm{m}$ from the cell body; SAK channels were recorded from both the cell body and growth cone of this cell (Fig. 3, $a$, $b$ ). This growth cone (Fig. $2 E$ ) and that in Figure 2, $B, C$, approach the minimum size from which single-channel recordings were successfully made. Patch recordings were not made on lamellae or microspikes, but note that growth cone recordings were obtained only a few micrometers from these structures (see Fig. 2, $B, C, E$ ), where the cell thickens slightly.

\section{Growth cone SAK channel stretch sensitivity}

SAK channel openings generally occurred in bursts as illustrated in the lower trace of Figure 4. A typical response to suction is demonstrated in the upper trace, where, on this time scale, individual channel openings (outward current) appear as spikes. During suction, with the increased membrane tension, the rate of opening and the probability of multiple open channels (up to 3 channels in this case) increased. Upon release, activity subsided to the presuction level. Other channels recorded from the growth cones displayed no stretch-activation under the range of recording conditions (i.e., pressure and voltage excursions and various salines) described in this paper. We have, however, recently observed a low-conductance $\mathrm{K}^{+}$channel inactivated by stretch (Morris and Sigurdson, 1989); it occurs in growth cones as well as cell bodies.

The lower trace of Figure 4 contains several low-conductance events that appear as small outward current shifts from the baseline. Such events were routinely excluded from the quantitative analyses described below.

Figure $5 a$ shows single-channel recordings with no applied suction, as well as suction sufficient to begin activating the channels. Such data were used to construct the curve shown in Figure $5 b$. The open probability increased steeply beyond a "threshold" 
a)

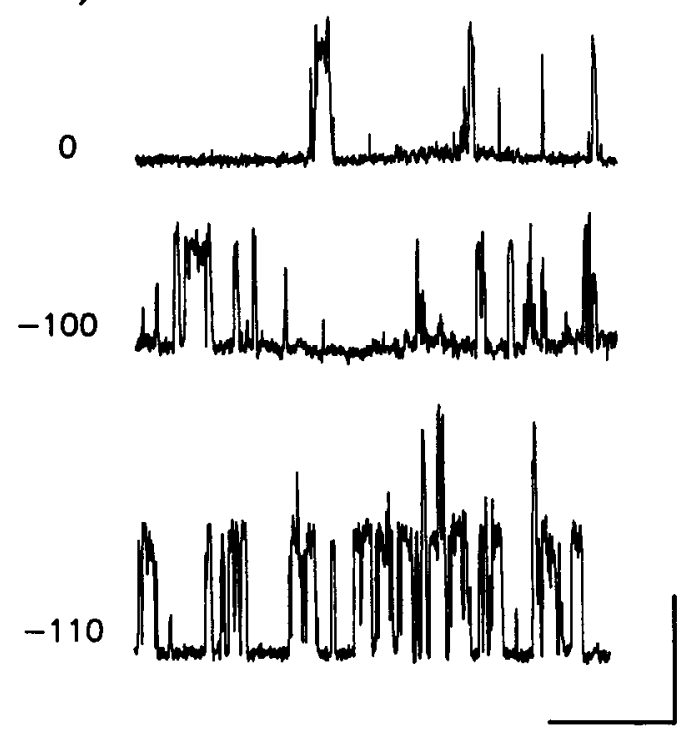

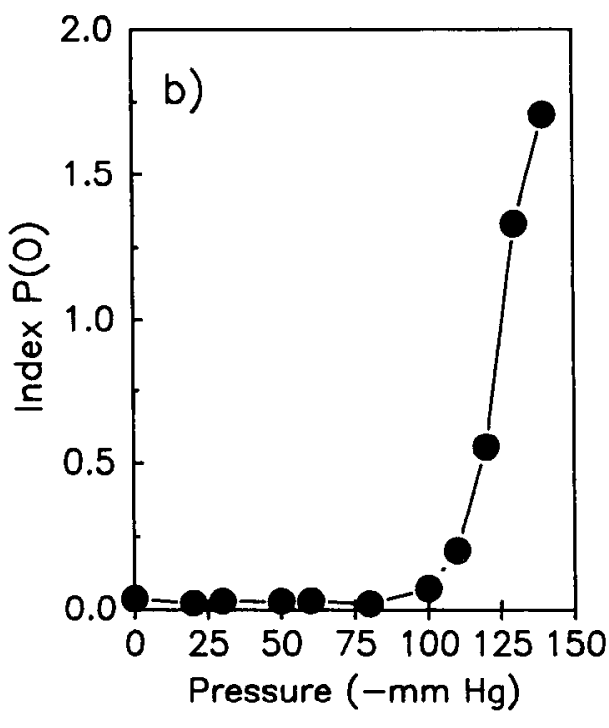

Figure 5. Effect of pressure on SAK channel activity, $a$, Recordings at indicated suction $(\mathrm{mm} \mathrm{Hg}$ ) applied by the pressure transducer. Note that channel open probability appears to increase by a reduction of closed intervals, yielding more openings per unit time. $V_{m}, 70$ $\mathrm{mV}$. Scale, $5 \mathrm{pA}$ and $50 \mathrm{msec} . b$, Open probability data for the same patch shown in $a$. pressure. Thresholds in the range of -50 to $-100 \mathrm{~mm} \mathrm{Hg}$ were observed for various patches. Usually $P(\mathrm{O})$ curves are expected to saturate at higher pressures when all channels are recruited (see Sigurdson et al., 1987b), but in the example shown in Figure $5 b$, the membrane ruptured at $-140 \mathrm{~mm} \mathrm{Hg}$. The index $P(\mathrm{O})$ at this highest experimental pressure is a reflection of the average channel activity seen over a period of about $15 \mathrm{sec}$ but is deceptively low as an indicator of the number of SAK channels present. As many as 8 channels (as opposed to the average of 1.8) were open simultaneously at some points, indicating that at least 8 channels must have been present in this patch. In general, patches from growth cones had similar SAK channel density to those from cell bodies $(\sim 4-8 /$ patch; corresponding to a density of $\sim 1-2 / \mu \mathrm{m}^{2}$ (see Guharay and Sachs, 1984; Sigurdson et al., 1987a)).

The SAK channel of Lymnaea heart cells is insensitive to intracellular $\mathrm{Ca}^{2+}$ (Sigurdson et al., 1987a), as is the neuronal cell body SAK channel (W. J. Sigurdson and C. E. Morris, unpublished observations). $\mathrm{Ca}^{2+}$ insensitivity of growth cone SAK channels was confirmed using inside-out patches $(50 \mathrm{~mm}$ $\mathrm{KCl}$ saline in pipette) which contained both $\mathrm{Ca}^{2+}$-activated $\mathrm{K}^{+}$ channels (Lux et al., 1981) and SAK channels. When these patches were perfused with a low $\mathrm{Ca}^{2+}$ solution (not shown) which silenced the $\mathrm{Ca}^{2+}$-activated $\mathrm{K}^{+}$channels, the SAK channels remained activatable by suction.

More detailed kinetic analysis of the recordings used to generate Figure $5 b$ was possible for $0,-100,-110$, and $-120 \mathrm{~mm}$ $\mathrm{Hg}$. This allowed us to ask which of the kinetic parameters contributes to the stretch-induced increase in $P(\mathrm{O})$. At all pressures, open-time distributions were best fit to a sum of 2 exponentials (Fig. 6), while closed times (histogram not shown) were best fit to a sum of 3 exponentials (see Table 1). The number of open and closed times and the values of their constants (mean dwell times) are in good accord with those reported for Lymnaea heart SAK channels (Sigurdson et al., 1987a). In principle, increased open times and/or decreased closed times could be responsible for increased $P(\mathrm{O})$. A pronounced effect of increasing tension is the progressive decrease of the longest closed time. This coincides with what has been observed for other stretch- sensitive channels, where a between-bursts closed time is most affected by stretch (Guharay and Sachs, 1984; Sigurdson et al., 1987a).

\section{SAK I/V relations}

$I / V$ relations of the stretch-sensitive channel in growth cones were determined under near-physiological ionic conditions (cellattached, NS in pipette and bath) as well as with high- $\mathrm{K}^{+}$saline (Fig. 7). For each voltage, suction was applied to activate the channels and thus unambiguously distinguish the SAK channels from stretch-insensitive channels. With NS in the pipette, the zero-current potential for stretch-activated currents was near the resting potential of the cell. With $50 \mathrm{mM} \mathrm{KCl}$ saline in the pipette, the zero-current potential shifted approximately $50 \mathrm{mV}$ to the right, a shift that would be in accord with the altered $\mathrm{K}^{+}$ equilibrium potential. As expected for a $\mathrm{K}^{+}$-selective channel, when excised patches were exposed to symmetrical NS and suction was applied, we observed no channel activity. Con-

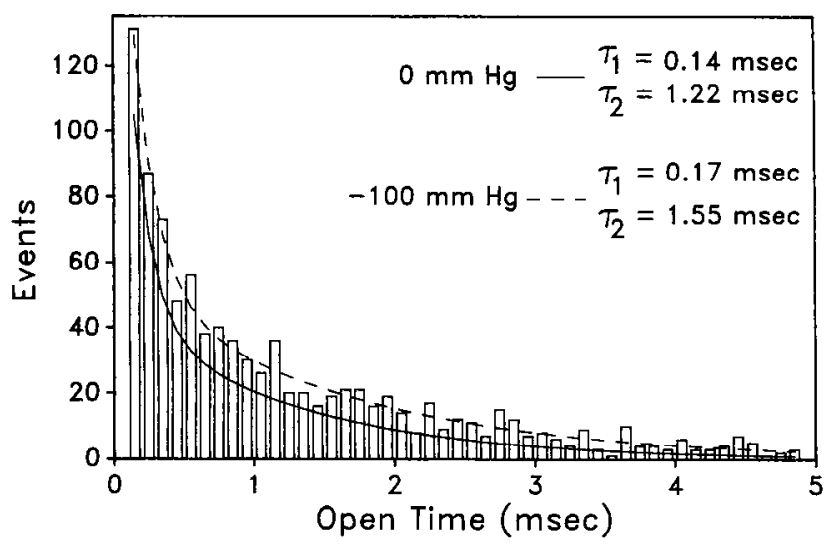

Figure 6. Open time histogram of growth cone SAK channels. Superimposed on the histogram (for $-100 \mathrm{~mm} \mathrm{Hg}$ ) are best fit curves for a sum of 2 exponentials to the $0 \mathrm{~mm} \mathrm{Hg}$ data (solid line; histogram not shown; total number of events was 788) and to the $-100 \mathrm{~mm} \mathrm{Hg}$ data (dashed line; total number of events was 1168). Error bounds for the indicated open time constants are given in Table 1. 


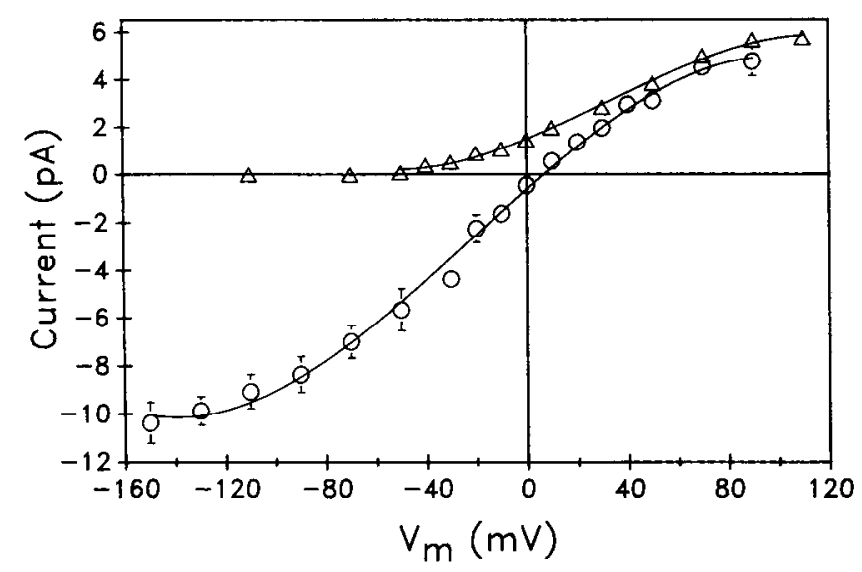

Figure 7. $\quad I / V$ relations for growth cone SAK channels. Triangles, NS in pipette; circles, $50 \mathrm{~mm} \mathrm{KCl}$ saline in pipette. Each curve (lines fit by eye) incorporates data from 4 patches; error bars are standard errors and, where not shown, are contained within the symbols. The steepest portions of the NS and $50 \mathrm{~mm} \mathrm{KCl}$ curves correspond to slope conductances of $44 \mathrm{pS}$ and $80 \mathrm{pS}$, respcctivcly.

versely, excised patches exposed to $50 \mathrm{~mm} \mathrm{KCl}$ in the pipette with $\mathrm{NS}$ in the bath (symmetrical $\mathrm{Cl}^{-}$, asymmetrical $\mathrm{K}^{+}$and $\mathrm{Na}^{+}$) demonstrated stretch-activated inward current, but not outward current. This is consistent with a channel permeable to $\mathrm{K}^{+}$and not to $\mathrm{Na}^{+}$or $\mathrm{Cl}^{-}$. Nonlinearities in single- $\mathrm{K}^{+}$channel $I / V$ relations, such as those seen in Figure 7 (except for the nonlinearity at the foot of the NS curve, which is predicted by electrodiffusion for a $\mathrm{K}^{+}$channel under asymmetric $\mathrm{K}^{+}$), can generally be attributed to effects of voltage on ion permeation through a multi-ion channel (Yellen, 1984a, 1987) and to apparent attenuation produced by high-frequency flickering at large polarization (Yellen, 1984b).

\section{Quinidine blocks SAK channels}

The $\mathrm{K}^{+}$channel blocker, quinidine, blocks cell body SAK channels in a dose-dependent manner (Sigurdson et al., 1987b); 1 mu produces a flickery block (Yellen, 1984b) or, in some cases, a full block of SAK channel currents. For growth cone SAK channels, this concentration of quinidine induced flickery block in 3 of 4 patches. The fourth patch was silent.

\section{Discussion}

It has been demonstrated that growing neurites, like fibroblastic cells, experience varying degrees of tension associated with their motility (Dembo and Harris, 1981; Bray, 1987; Letourneau et al., 1987). Accordingly, some models of neurite elongation and neurogenesis incorporate tension as a regulatory element (Bray, 1984; Gordon and Brodland, 1987; Letourneau et al., 1987; Bray and White, 1988; though see Goldberg and Burmeister, $1986,1988)$. Yet despite the clearly mechanical nature of neurite motility, no mechanism has been identified by which tension could be sensed. Stretch-activated channels would seem to be ideally suited for this role.

Although the mechanism by which stretch-sensitive channels transduce membrane tension is still speculative, there is evidence that the channels are tied into the underlying cortical cytoskeleton. In particular, Guharay and Sachs (1984) showed that cytochalasin increased the stretch-sensitivity of SA channels in skeletal muscle. Their interpretation (Sachs, 1988) was that actin filaments normally relieve tension on the membrane cytoskeletal elements which directly apply tension to the channels. These unknown elements may involve spectrin/ankyrin; the density of $\mathrm{Na}^{+}$channels and glutamate receptors has recently been shown to be controlled by anchorage to these proteins (Siman et al., 1985; Srinivasan et al., 1988). For stretch-activated channels, one could envisage that such connections were specialized to render the channels sensitive to membrane tension.

A question that we wished to address by recording from growth cones was whether newly incorporated membrane would contain stretch-sensitive channels. If the channel's tension-sensing elements were not in place, then even if the channel were present, stretch would not activate it. Incorporation of plasmalemma by exocytosis is believed to take place in the main body of the growth cone (Tosney and Wessells, 1983; Goldberg and Burmeister, 1986). Since we found SAK channels in all growth cones examined, the simplest conclusion is that newly incorporated membrane contains the channel and its tension-sensing element(s) as an already functional unit, or at least in a state that allows rapid acquisition of full function.

If SAK channels play a role in regulation of neurite extension, the membrane tensions exerted during growth cone movement should match the range of tensions required for activation. Traction forces produced by fibroblast locomotion can exceed $10^{-3}$

Table 1. Kinetic analysis of growth cone SAK channels ${ }^{a}$

\begin{tabular}{|c|c|c|c|c|c|c|}
\hline \multirow[b]{2}{*}{$\begin{array}{l}\text { Pressure } \\
(\mathrm{mm} \mathrm{Hg})\end{array}$} & \multirow[b]{2}{*}{$\begin{array}{l}\text { Index } \\
P(\mathrm{O})\end{array}$} & \multicolumn{2}{|l|}{ Open times } & \multicolumn{3}{|l|}{ Closed times $^{b}$} \\
\hline & & $\begin{array}{l}\tau_{1} \\
(\mathrm{msec})\end{array}$ & $\begin{array}{l}\tau_{2} \\
(\mathrm{msec})\end{array}$ & $\begin{array}{l}\tau_{1} \\
\text { (msec) }\end{array}$ & $\begin{array}{l}\tau_{2} \\
\text { (msec) }\end{array}$ & $\begin{array}{l}\tau_{3} \\
\text { (msec) }\end{array}$ \\
\hline 0 & 0.038 & $0.14 \pm 0.03$ & $1.22 \pm 0.12$ & $0.3 \pm 0.05$ & $1.29 \pm 0.32$ & $\begin{array}{l}57.2 \pm 8.5 \\
(57.9)\end{array}$ \\
\hline-100 & 0.073 & $0.17 \pm 0.02$ & $1.55 \pm 0.09$ & $0.18 \pm 0.02$ & $1.46 \pm 0.12$ & $\begin{array}{l}37.2 \pm 4.5 \\
(40.6)\end{array}$ \\
\hline-110 & 0.203 & - & - & - & - & $(20.0)$ \\
\hline-120 & 0.555 & - & - & - & - & $(6.8)$ \\
\hline
\end{tabular}

${ }^{a}$ Same patch as used for Figure 4. N.B. Ratios of $P(O)$ s relative to $0 \mathrm{~mm} \mathrm{Hg}$ are $1.92,5.34$ and 14.5 for $-100,-110$ and $-120 \mathrm{~mm} \mathrm{Hg}$, respectively.

${ }^{b}$ Beyond $-100 \mathrm{~mm} \mathrm{Hg}$ the records contained too many multiple openings for generating the histograms needed for curve fitting. Instead, an approximation to $\tau_{3}$ was obtained by averaging the closed (zero current) intervals greater than $2 \mathrm{msec}$ and subtracting this cutoff time from the average (Colquhoun and Sigworth, 1983, equation 50). Note that when both approaches are used where $P(O)$ is low $(0$ and $-100 \mathrm{~mm} \mathrm{Hg})$, the estimated average (given in brackets) falls within the error bounds of the values obtained by fitting. 
$\mathrm{dyn} / \mu \mathrm{m}$ (Harris et al., 1980), while forces needed to move particles over the cell surface are much smaller, $10^{-8} \mathrm{dyn} / \mu \mathrm{m}$ (Dembo and Harris, 1981). The experimental tensions applied to the growth cone membrane in this study fall within this range (6.7 $\times 10^{-4} \mathrm{dyn} / \mu \mathrm{m}$ for $-100 \mathrm{~mm} \mathrm{Hg}$ in a typical patch, based on the calculations of Guharay and Sachs, 1984), but we cannot as yet relate this tension to traction and/or other forces experienced by growth cones. Evidence that physiologically relevant tensions affect stretch-sensitive channels comes from a recent report on teleost embryos (Medina and Bregestovski, 1988), in which tensions generated during cytokinesis activate SAK channels.

The potential role of any channel is constrained by its ion selectivity: $\mathrm{K}^{+}$channels typically hyperpolarize, whereas (nonselective) cation or $\mathrm{Na}^{+}$channels depolarize the membrane. The $I / V$ relations show that the growth cone stretch-activated channel is essentially identical to that in the soma, namely, $\mathrm{K}^{+}$selective (Sigurdson et al., 1987b). Vertebrate SAK channels have been identified (Sackin, 1987, 1989; Ding et al., 1988; Medina and Bregestovski, 1988), but the most-studied vertebrate stretchsensitive channcl is a cation channel that allows $\mathrm{K}^{+}, \mathrm{Na}^{+}$(Cooper et al., 1986; Sachs, 1987) and $\mathrm{Ca}^{2+}$ (Christensen, 1987; Kirber et al., 1988) to permeate. Activation of either class of channel could profoundly affect local intracellular $\mathrm{Ca}^{2+}$ concentrations (Lipscombe et al., 1988). The cation channels would act to increase $\mathrm{Ca}^{2+}$, indirectly by depolarizing the membrane and directly by passing $\mathrm{Ca}^{2+}$ ions. Activation of $\mathrm{K}^{+}$channels, on the other hand, would stabilize the membrane potential near $E_{\mathrm{K}}$, thereby decreasing influx of $\mathrm{Ca}^{2+}$ through its voltage-gated channels. Motile growth cones in Helisoma have recently been shown to have higher free $\mathrm{Ca}^{2+}$ levels than those that have stopped growing (Cohan et al., 1987). This $\mathrm{Ca}^{2+}$-driven motility could employ tension-sensitive $\mathrm{K}^{+}$channels as a negative-feedback mechanism.

In a recent summary scheme of "known and suspected pathways of $\mathrm{Ca}^{++}$regulation in the growth cone," Kater et al. (1988) feature a variety of ion channels. SA channels can probably now be added to this scheme under the heading, "suspected." Much of the work that led to the present picture of $\mathrm{Ca}^{2+}$ regulation was done on Helisoma, a snail of the same suborder (Basommatophora) as Lymnaea. Since we have shown that SAK channels also occur in neurons of a more distantly related gastropod (Cepaea nemoralis, from the same family as Helix in the Suborder Stylommatophora) (Bedard et al., 1988), we feel justified in presuming that the stretch-activated channels are widely distributed in pulmonate snails. It would be surprising if they were not found in Helisoma neurons.

The presence of mechanosensitive integral membrane proteins in the growth cone (see also Morris and Sigurdson, 1989) raises the possibility that additional (perhaps electrically silent) proteins might likewise possess mechanotransduction machinery, giving them access to information about growth cone motility that could help them govern the pace and/or direction of neurite elongation.

\section{References}

Bedard, E., W. J. Sigurdson, and C. E. Morris (1988) Stretch-activated (SA) channels in the neurons of Cepaca (Helicideae) and Lymnaea. Biophys. J. 53: 154a.

Bray, D. (1984) Axonal growth in response to experimentally applied mechanical tension. Dev. Biol. 102: 379-389.

Bray, D. (1987) Growth cones: Do they pull or are they pushed? Trends Neurosci. 10: 431-434.
Bray, D., and J. G. White (1988) Cortical flow in animal cells. Science 239: 883-888.

Christensen, O. (1987) Mediation of cell volume regulation by $\mathrm{Ca}^{2+}$ influx through stretch-activated channels. Nature 330:66-68.

Cohan, C. S., J. A. Connor, and S. B. Kater (1987) Electrically and chemically mediated increases in intracellular calcium in neuronal growth cones. J. Neurosci. 7: 3588-3599.

Colquhoun, D., and F. Sigworth (1983) Fitting and statistical analysis of single-channel records. In Single-Channel Recording, B. Sakmann and E. Neher, eds., pp. 191-263, Plenum, New York.

Cooper, K. E., J. M. Tang, J. L. Rae, and R. S. Eisenberg (1986) A cation channel in frog lens epithelium responsive to pressure and calcium. J. Membr. Biol. 93: 259-269.

Corey, D. P., and C. F. Stevens (1983) Science and technology of patch-recording electrodes. In Single-Channel Recording, B. Sakmann and E. Neher, eds., pp. 53-68, Plenum, New York.

Dembo, M., and A. K. Harris (1981) Motion of particles adhering to the leading lamella of crawling cells. J. Cell Biol. 91: 528-536.

Ding, J.-P., X.-C. Yang, G. L. Bowman, and F. Sachs (1988) Stretchactivated ion channel in rat astrocytes in primary culture. Soc. Neurosci. Abstr. 425.5.

Falke, L., and S. Misler (1988) Ion channel activity during osmoregulation in clonal neuroblastoma (N1E115) cells. Biophys. J. 53:412a.

Goldberg, D. J., and D. W. Burmeister (1986) Stages in axon formation: Observations of growth of Aplysia axons in culture using video-enhanced contrast-Differential interference contrast microscopy. J. Cell Biol. 103: 1921-1931.

Goldberg, D. J., and D. W. Burmeister (1988) Growth cone movement. Trends Neurosci. 11: 257-258.

Gordon, R., and G. W. Brodland (1987) The cytoskeletal mechanics of brain morphogenesis. Cell Biophys. 11: 177-238.

Guharay, F., and F. Sachs (1984) Stretch-activated single ion channel currents in tissue-cultured embryonic chick skeletal muscle. J. Physiol. (Lond.) 352: 685-701.

Hamill, O. P., M. E. Neher, B. Sakmann, and F. J. Sigworth (1981) Improved patch-clamp techniques for high resolution current recording from cells and cell-free membrane patches. Pfluegers Arch. 391: 85-100.

Harris, A. K., P. Wild, and D. Stopak (1980) Silicone rubber substrata: A new wrinkle in the study of cell locomotion. Science 208: 177-179.

Kater, S. B., and M. P. Mattson (1988) Extrinsic and intrinsic regulators of neurite outgrowth and synaptogenesis in isolated identified Helisoma neurons in culture. In Cell Culture Approaches to Invertebrate Neuroscience, D. J. Beadle, G. Lees, and S. B. Kater, eds., pp. 1-31, Academic, Toronto.

Kater, S. B., M. P. Mattson, C. Cohan, and J. Connor (1988) Calcium regulation of the neuronal growth cone. Trends Neurosci. 11:315320.

Kirber, M. T., J. V. Walsh, Jr., and J. J. Singer (1988) Stretch-activated ion channels in smooth muscle: A mechanism for the initiation of stretch-induced contraction. Pfluegers Arch. 412: 339-345.

Kullberg, R. (1987) Stretch-activated ion channels in bacteria and animal cell membranes. Trends Neurosci. 10:387-388.

Lackie, J. M. (1986) Cell Movement and Cell Behavior, Allen and Unwin, Boston.

Letourneau, P. C., T. A. Schattuck, and A. H. Ressler (1987) "Pull" and "push" in neurite elongation: Observations on the effects of different concentrations of cytochalasin B and taxol. Cell Motil. Cytoskel. 8: 193-209.

Lipscombe, D., D. V. Madison, M. Poenie, H. Reuter, R. Y. Tsien, and R. W. Tsien (1988) Spatial distribution of calcium and cytosolic calcium transients in growth cones and cell bodies of sympathetic neurons. Proc. Natl. Acad. Sci. USA 85: 2398-2402.

Lux, H. D., E. Neher, and A. Marty (1981) Single channel activity with the calcium dependent outward current in Helix pomatia. Pfluegers Arch. 389: 293-295.

Medina, I. R., and P. D. Bregestovski (1988) Stretch-activated ion channels modulate the resting membrane potential during early embryogenesis. Proc. R. Soc. London [Biol.] 235: 95-102.

Morris, C. E., and W. J. Sigurdson (1989) Stretch-inactivated ion channels coexist with stretch-activated ion channels. Science 243: 807-809.

Sachs, F. (1987) Baroreceptor mechanisms at the cellular level. Fed. Proc. 46: 12-16. 
Sachs, F. (1988) Mechanical transduction in biological systems. CRC Crit. Rev. Biomed. Engin. 16: 141-169.

Sackin, H. (1987) Stretch-activated potassium channels in renal proximal tubule. Am. J. Physiol. 253: F1253-F1262.

Sackin, H. (1989) A stretch-activated $\mathrm{K}^{+}$channel sensitive to cell volume. Proc. Natl. Acad. Sci. USA 86: 1731-1735.

Siegelbaum, S. A., F. Belardetti, J. S. Camardo, and M. J. Shuster (1986) Modulation of the serotonin-sensitive potassium channel in Aplysia sensory neurone cell body and growth cone. J. Exp. Biol. 124: 287306.

Sigurdson, W. J., C. E. Morris, B. L. Brezden, and D. R. Gardner (1987a) Stretch activation of a $\mathrm{K}$ channel in molluscan heart cells. J. Exp. Biol. 127: 191-209.

Sigurdson, W. J., E. Bedard, and C. E. Morris (1987b) Stretch-activated (SA) channels in molluscan neurons. Biophys. J. 51: 50a.
Siman, R., M. Baudry, and G. Lynch (1985) Regulation of glutamate receptor binding by the cytoskeletal protein fodrin. Nature $313: 225-$ 228.

Srinivasan, Y., L. Elmer, J. Davis, V. Bennett, and K. Angelides (1988) Ankyrin and spectrin associate with voltage-dependent sodium channels in brain. Nature 333: 177-180.

Tosney, K. W., and N. K. Wessells (1983) Neuronal motility: The ultrastructure of veils and microspikes correlates with their motile activities. J. Cell Sci. 61: 389-411.

Yellen, G. (1984a) Ionic permeation and blockade in $\mathrm{Ca}^{2+}$-activated $\mathrm{K}^{+}$channels of bovine chromaffin celis. J. Gen. Physiol. 84: 157-186.

Yellen, G. (1984b) Relief of $\mathrm{Na}^{+}$block of $\mathrm{Ca}^{2+}$-activated $\mathrm{K}^{+}$channels by external cations. J. Gen. Physiol. 84: 187-199.

Yellen, G. (1987) Permeation in potassium channels: Implications for channel structure. Ann. Rev. Biophys. Biophys. Chem. 16: 227-246. 